Editorial

\title{
Suicidality and mismanaged care
}

Volume 4 Issue 2 - 2015

\section{Editorial}

A 24year old man bolts from his home after threatening to kill his parents and himself. After a brief standoff with the police, he is taken a community hospital and discharged the next day. A 14year old female inexplicably ingests 30 extra strength Tylenol and goes to sleep for the night, never saying a word to her parents. Remarkably, she awakens the next morning. Violently ill, she is taken to the hospital and released to her parents after being medically "cleared." Lastly, a 30year old man with a history of bipolar disorder and chronic opiate abuse is brought to the emergency room after an overdose. $\mathrm{He}$ is given Narcan and released the following day. What do these individuals have in common? A hospital stay of less than three days. Importantly, these stays were abbreviated not because the treating clinicians disputed the seriousness of the risk these patients posed, but because the insurers denied any further coverage for inpatient services. It made no difference whether the violence was directed at self or others, whether the patient was an adult or a minor; in what has now become a frequent refrain from insurance reviewers, continued inpatient treatment was not deemed "medically necessary."

According to HCUP, ${ }^{1}$ these anecdotes comport with the national average of approximately 2.7 days of hospitalization following serious suicide attempts. Three times this number of U.S. citizens report serious suicide ideation, with over one million attempts made annually. ${ }^{2}$

The numbers speak for themselves and seem to cry out for increased outreach and provision of services. Yet, the reality of healthcare in the U.S. is that it is access to policy benefits is difficult, placing those who are perhaps least able to negotiate the bureaucratic maze of the healthcare industry in the unenviable position of having to fend for themselves. Rather than listening to the concerns of treating clinicians, determinations are made by individuals with rather clear conflicts of interest - the latter's mandate is to limit care and they have the power to do so. That adverse decisions are rationalized not as denials of care, but as denials of reimbursement to providers and institutions for medically unnecessary services strains credulity. While the escalation of medical costs and its containment is a legitimate concern, let's not place the burden of cost-cutting on our most vulnerable and needy citizens. Suicidality is not only an urgent concern, it is an ultimate concern. Proper evaluation and treatment by highly-trained mental health professionals is essential and often can be provided only in an inpatient setting where patient safety is a priority. It is an ethical obligation of those involved to insure that those most in need receive proper care.
Ronald C Naso

American Board and Academy of Psychoanalysis, USA

Correspondence: Ronald C Naso,American Board and Academy of Psychoanalysis, 2777 Summer Street, Suite 504B, Stamford, CT 06905, USA, Email renphd@gmail.com

Received: November II, 2015 | Published: November 17, 2015

\section{Acknowledgments}

None.

\section{Conflicts of interest}

Author declares there are no conflicts of interest.

\section{Funding}

None.

\section{References}

1. Healthcare Cost and Utilization Project (HCUP). Agency for Healthcare Research and Quality, Rockville, MD, USA. 2015.

2. Behavioral Health Trends in the United States: Results from the 2014 National Survey on Drug Use and Health (2014) 